Relationship Between Perceived In-Cabin Air Quality and Truck Drivers' Self-Reported Health and Alertness

Author(s): Richard Tay, Zhongchao Tan and Xiaoying Cheng

Source: Journal of the Transportation Research Forum, Vol. 47, No. 4 (Fall 2008), pp. 115-133

Published by: Transportation Research Forum

Stable URL: http://www.trforum.org/journal

The Transportation Research Forum, founded in 1958, is an independent, nonprofit organization of transportation professionals who conduct, use, and benefit from research. Its purpose is to provide an impartial meeting ground for carriers, shippers, government officials, consultants, university researchers, suppliers, and others seeking exchange of information and ideas related to both passenger and freight transportation. More information on the Transportation Research Forum can be found on the Web at www.trforum.org. 


\title{
Relationship Between Perceived In-Cabin Air Quality and Truck Drivers' Self-Reported Health and Alertness
}

\author{
by Richard Tay, Zhongchao Tan and Xiaoying Cheng
}

This study surveyed 253 truck drivers and found that many drivers scored poorly on the Stanford and Epworth sleepiness scales indicating that they may not be as alert as they should be while driving. Moreover, those who rated the air in their truck cabins as fresh reported less irritation to their eyes, noses, throats, and skin, scored better in both sleepiness scales, and reported fewer sleeprelated medical symptoms. Finally, the results of the ordinal logistic model indicate that drivers ' perceptions of the air quality in their truck cabins are significantly related to their alertness during a trip.

\section{INTRODUCTION}

Trucking is one of the most important industries in North America. There were over three million truck drivers in the U.S. in 2004 and 1.3 million of them were long-haul heavy-duty truck drivers (American Trucking Associations 2005). Over the next 10 years, economic growth will give rise to a need for a $2.2 \%$ average annual increase in the number of long-haul heavy-duty truck drivers, or an additional 320,000 jobs overall in the U.S. Moreover, there were 13.4 million two-way trips made across the Canada-U.S. border in 2004 and this traffic is also expected to grow by about $2.2 \%$ per year (Transport Canada 2004).

Since a significant share of the truck traffic involves long-haul trips, drivers accumulate very high mileage on the roads. It is not surprising, therefore, that crashes involving trucks are a major concern in road safety. In Canada, for example, crashes involving commercial vehicles account for approximately $20 \%$ of all traffic fatalities each year and are one of the explicitly targeted areas in the national road safety strategy (Transport Canada 2002). Similarly, truck drivers accounted for 5,375 deaths (17.6 per 100,000 full-time equivalent workers) in the United States between 1992 and 2001, the highest number and rate for any single occupation (NIOSH 2004).

Although the factors contributing to commercial truck crashes are complex, driving while fatigued is widely accepted as one of the main contributing factors (Dingus et al. 2006, Gander et al. 2006; Hanowski et al. 2003; Williamson et al. 2001; Häkkänen and Summala 2001; Baas et al. 2000; Arnold et al. 1997; Feyer et al. 1997; Williamson et al. 1996). The factors influencing driver fatigue in the general driving population, and among commercial trucking in particular, have been a topic of research interest in road safety. Most studies on truck drivers thus far have focused on biological factors such as the overall health of the drivers and circadian rhythm or organizational factors such as work hours and incentives. Little research, however, has been done on examining the effects of vehicular and environmental factors, especially environmental factors within truck cabins, on the health and safety of occupants and other road users.

An environmental factor that merits further investigation is air quality in truck cabins. Since drivers spend most of their working hours, as well as large portions of their sleeping hours, in trucks, in-cabin air quality is expected to have a significant impact on their overall health, sleepiness, and fatigue levels (Gillberg et al. 2003; Dingus et al. 2001). If the concentration of air pollutants is high 
enough within this limited space, it could impair the driver's health and sleep quality. The driver may not feel as refreshed even after an overnight sleep. The purpose of this study, therefore, is to examine the perceptions of truck drivers of in-cabin air quality and correlate these perceptions with their general alertness and health status. The knowledge gained will lay the foundation for future research that may eventually establish a causal link between in-truck air quality and the health and alertness of truck drivers.

\section{LITERATURE REVIEW}

The linkages between air quality and fatigue have been well-documented in other areas of research (Norbäck et al. 1990; Thibeault 1997; Gander et al. 1998; Wargocki 1999; Akerstedt 2000). However, little attention has been devoted to the influence of in-vehicle air quality on drivers' health in general and alertness in particular, which is also likely to affect their driving performance and the safety of all road users. Among the likely pollutants found in vehicles, several are expected to have effects on drivers' health and alertness. Besides carbon dioxide $\left(\mathrm{CO}_{2}\right)$ which could be produced by the driver's respiration or as a part of vehicle emission, other gases like carbon monoxide (CO) and nitrogen dioxide $\left(\mathrm{NO}_{2}\right)$, which are also common gases in emissions, may have detrimental effects on a driver's health and alertness (Sato 2005; Cheng et al. 2006; Penney 2007). In addition, particulate matter (PM) is an important health-threatening pollutant.

$\mathrm{CO}_{2}$ has obvious health effects in humans at various levels. At the concentration level of 700 parts per million (ppm) or lower, its adverse effect is negligible, but people start feeling uncomfortable when its concentration reaches 800 ppm (MDH 2004). In an environment where $\mathrm{CO}_{2}$ concentration reaches 5,000 ppm, people feel fatigued and lose concentration (OSHA 1995); and, at 20,000 ppm, they breathe at $150 \%$ of the normal rate. When the concentration of $\mathrm{CO}_{2}$ increases to $30,000 \mathrm{ppm}$, the heart rate and blood pressure increase (Schwarzberg 1993), hearing can be impaired, and most people feel dizzy.

When subjects are exposed to $\mathrm{CO}$ concentrations above $90 \mathrm{ppm}$ for a long time, they may experience adverse effects on their hearts and brains and it could lead to low children's birth weights. Angina, impaired vision, and reduced brain function may also result (Townsend and Maynard 2002). When exposed to $200 \mathrm{ppm}$ of $\mathrm{CO}$, most people experience slight headaches, tiredness, dizziness, and nausea after two to three hours. At $400 \mathrm{ppm}$, frontal headache occurs within one to two hours, and life can be threatened after three hours. At $800 \mathrm{ppm}$, people experience dizziness, nausea, and convulsions within 45 minutes, are unconscious within two hours, and die in two to three hours. At $1,600 \mathrm{ppm}$, headache, dizziness and nausea occur within 20 minutes and death within an hour.

Simoni et al. (2002) showed that there is a close relationship between indoor $\mathrm{NO}_{2}$ levels of 33 ppm in winter and increased occurrence of acute respiratory symptoms in non-smoking adults. At higher $\mathrm{NO}_{2}$ levels, bronchitic and asthmatic symptoms are significantly more prevalent. They also reported that these health effects were associated with the duration of the exposure. Similar results were obtained when subjects were exposed to a low dose of $\mathrm{NO}_{2}$ of 10 parts per billion (ppb) for a longer duration (five hours) and to a higher $\mathrm{NO}_{2}$ concentration (i.e., $50 \mathrm{ppb}$ ) for a short duration (one hour). Exposure to $\mathrm{NO}_{2}$ of $200 \mathrm{ppm}$ or greater immediately endangers life. At levels of 50 to100 ppm, $\mathrm{NO}_{2}$ impairs lung function and irritates the eyes, nose, and throat (Alberts 1994). Moreover, there is evidence that $\mathrm{NO}_{2}$ may cause lung damage at concentrations of $300 \mathrm{ppb}$ or higher (Samet and Cushing 1997).

Besides these gases, indoor particulate matter presents a risk to public health (Cheng et al. 2006; Wallace and Smith 2007). Particles smaller than one micrometer (submicron particles) pose more threat to indoor occupants because they can penetrate deeply into the respiratory system. A recent workshop organized by The Royal Society concluded that there was some evidence that submicron particles, especially nanoparticles, translocated from the lungs to the brain and blood causing increased blood coagulation and inflammogenic effects (Dreher 2004). In addition, particulate matter in a truck cabin is likely to contain several toxic substances that may be harmful 
to the human body. The main sources of particulate matter in truck cabins are road dust, emissions, and cigarette smoke, which may contain chemicals such as lead, barium, magnesium, cobalt, and manganese (Tan and Tay 2008).

In one of the few studies that examined engineering and other environmental effects, Galatsis et al. (2000) linked in-cabin air quality in cars with fatigue and indirectly with road safety. They found that it was necessary to install gas sensors in enclosed spaces such as inside cars where air quality can be improved by controlling the ventilation system. When the concentrations of pollutants monitored are high, an alarm will be activated to inform the occupants to open the ventilation system, thereby keeping the air quality in the cabin as good as the ambient air. Sato (2002) suggested that further studies focusing on the effects of air quality on safe and comfortable driving should be conducted.

Several studies have also been conducted to understand the effect and mechanisms of selfpollution in transportation vehicles such as school buses and passenger cars (Chan and Chung 2003; Park et al. 1998; Rodes et al. 1998). In these vehicles, some of the engine exhaust can enter the cabin through open windows and the ventilation systems and degrade the quality of the air inside the cabin. Although no study has been conducted on heavy trucks, it is expected that this self-pollution mechanism also exists for these types of vehicles.

In a recent review of the literature, Cheng et al. (2006) found no publicly available reports documenting in-cabin air quality in trucks. Tan et al. (2006a) developed and tested a portable air quality monitoring system, which was then deployed in an urban short-haul truck during the summer to measure gaseous pollution inside truck cabins. In a separate study, Tan et al. (2008) deployed an improved system during winter in an intercity truck to measure the same gaseous pollution and particulate matter as they did in the summer. Overall, their results indicated that gaseous concentrations (carbon monoxide, carbon dioxide, and nitrogen dioxide) were within the values recommended by the U.S. National Ambient Air Quality Standards most of the time, but thermal comfort levels (temperature and relative humidity) were outside the values recommended by the American Society for Heating, Refrigeration, Air-conditioning Engineers for a significant portion $(93 \%)$ of the time. They also found that readings for particulate matter (PM2.5) were one to 12 times higher than the recommended values for the entire period monitored. Overall, the limited physical data available on in-cabin air quality in trucks suggest that probably the air quality is not as good as it should be.

The above review shows limited information on drivers' perception of in-cabin air quality. If most truck drivers perceive the air in their cabins as clean and fresh, they would not raise any concern nor will they demand actions to be taken to improve it. On the other hand, drivers may perceive the air quality to be poor but little attention has been paid to this issue and thus, no data are available to support their concerns. Due to the limited knowledge available on the actual or perceived relationships between in-cabin air quality, health, and driver performance, there is currently no government or industry guideline to use.

\section{METHODOLOGY}

\section{Procedure}

The most logical method to examine the effects of in-cabin air quality on truck drivers' health and alertness is to physically measure in-cabin air quality and their state of alertness on trips. However, since in-cabin air quality is significantly affected by the outside environment, it has to be measured over an entire trip. To obtain such measurements for a relatively large sample of drivers, however, is beyond the scope of this study. Moreover, no simple measurement method is currently available to assess driver fatigue and alertness with an acceptable degree of reliability or validity. Therefore, the most appropriate method of collecting these data is by driver survey. Moreover, the use of subjective measures, as adopted in this study, has a strong foundation in the behavioral sciences, especially with respect to risk-taking behavior and road safety. It is important to point out that most 
of the drivers' decision making (especially the decision to continue driving or stopping for fresh air) is based on their perceptions of the environment and their mental states as opposed to the actual physical measurements of air quality.

A questionnaire was therefore designed to gather information on drivers' perception of air quality in their cabins and their self-reported health and alertness status. The part of the questionnaire survey focusing on health and alertness was designed using mostly standardized questions and measurement scales adopted from the literature (sleepiness scales or medical condition checklist). However, we were not able to find any standardized questionnaire or scales to use to measure perceived air quality. Hence, questions were developed to capture drivers' perception of in-cabin air quality. These questions were designed with the assistance of two managers from a trucking company in the City of Calgary, Alberta, Canada, and several researchers in road safety as well as environmental engineering.

The questionnaire was then pilot tested using a sample of graduate students in air quality and road safety as well as drivers from the same trucking company. To increase the response rate, the questionnaire was deliberately kept short so that it could be completed in less than 10 minutes because it was designed to be administered to the drivers while they were refueling their trucks in the middle of the Canadian winter. The survey was approved by the University of Calgary research ethics committee and conducted in accordance with its guidelines. Participation in the survey was strictly voluntary and participants were informed of their rights to withdraw at any time. They were also assured that the information collected would be kept confidential and only aggregate data would be published.

\section{Sample and Profile of Participants}

The revised questionnaire was subsequently administered to 253 truck drivers at two popular truck stops (gas stations with rest areas and eateries for trucks) in the city between January and March 2006, with the approval and support of the station managers. Less than $10 \%$ of the drivers approached declined to participate. The majority of the respondents were long-haul truck drivers and thus did not reside in Calgary. They came from as far as Tennessee and Connecticut in the United States. Although the sample was taken at truck stops, there is no reason to expect any systematic biases in the responses received. The profile of the respondents is very similar to that of drivers in the North American trucking industry (American Trucking Association 2005).

As shown in Table 1, the sample is dominated by middle-aged males $(79.2 \%$ aged between 35 and 65$)$ with over 10 years of driving experience (70.8\%). Most drivers drive alone $(85.7 \%)$ and drive on long-haul trips (73.7\%). They work long hours, with $91.2 \%$ working between nine and 15 hours per day and three-quarters working more than five days per week. Almost a quarter of the drivers sleep for six hours or less a day, which is less than the desired amount of sleep per day. Most of the drivers sleep in their trucks regularly, with $43.9 \%$ sleeping in the sleeper berth every day. These results suggest that they spend a very significant amount of their time in the truck cabins. 
Table 1: Truck Driver Profile

\begin{tabular}{lr}
\hline Driving Experience & \\
5 years or less & $14.6 \%$ \\
6 - 10 years & $14.6 \%$ \\
Over 10 years & $70.8 \%$ \\
\hline Usual Driving Mode & \\
$\quad$ Alone & $85.7 \%$ \\
Co-driver & $9.5 \%$ \\
Passenger & $4.8 \%$ \\
\hline Type of Trips & \\
Mostly Long Haul & $73.7 \%$ \\
Very Mixed & $21.4 \%$ \\
Mostly Short Haul & $4.9 \%$ \\
\hline Working Days per Week & \\
4 days or less & $4.4 \%$ \\
5 days & $20.5 \%$ \\
6 days & $40.6 \%$ \\
7 days & $34.5 \%$ \\
\hline Working Hours per Day & \\
8 hrs or less & $5.6 \%$ \\
$9-11$ hrs & $51.2 \%$ \\
$12-15$ hrs & $40.0 \%$ \\
16 hrs or more & $3.2 \%$ \\
\hline Sleeping Time per Day & \\
6 hrs or less & $24.3 \%$ \\
$7-9$ hrs & $61.9 \%$ \\
\hline Sleeping in Truck & $13.8 \%$ \\
Less than 3 times per week & $34.8 \%$ \\
$3-4$ times per week & $43.9 \%$ \\
\hline -6 times per week & \\
Every day & \\
\hline & \\
\hline
\end{tabular}

\section{Questionnaire and Material}

The questionnaire was designed to collect information on the drivers' perception of in-cabin air quality as well as their health profiles and self-reported driving performance. In addition to the standard questions on driving experience, work schedules, and time spent sleeping in the truck, the first section of the questionnaire gathered some information on drivers' perceptions of the usefulness of the 12 measures in helping them stay alert while driving (Table 2). Examples are "Taking a power nap," "Drinking coffee," and "Cooling the truck cabin." Data for these items were collected using a five-point scale ranging from $1=$ "not useful at all" to $5=$ "very useful." 
In-Cabin Air Quality

Table 2: Perceived Usefulness of Measures to Help Stay Alert (Percent)

\begin{tabular}{lrrrrrr}
\hline \multirow{2}{*}{ Measures } & $\begin{array}{c}\text { Not At All } \\
\text { Useful }\end{array}$ & $\begin{array}{c}\text { Slightly } \\
\text { Useful }\end{array}$ & $\begin{array}{c}\text { Moderately } \\
\text { Useful }\end{array}$ & $\begin{array}{c}\text { Fairly } \\
\text { Useful }\end{array}$ & $\begin{array}{c}\text { Very } \\
\text { Useful }\end{array}$ & Mean \\
\hline Taking a power nap & 10.9 & 7.1 & 15.1 & 26.8 & 40.2 & 3.78 \\
Stopping for fresh air \& stretching & 6.0 & 10.6 & 18.7 & 31.1 & 33.6 & 3.76 \\
Stopping to eat or drink & 10.1 & 8.0 & 20.2 & 28.6 & 33.2 & 3.67 \\
Cooling the truck cabin & 4.6 & 12.9 & 21.6 & 36.5 & 24.5 & 3.63 \\
Listening to music on cassette or CD & 9.8 & 13.2 & 24.3 & 26.0 & 26.8 & 3.47 \\
Listening to radio & 11.6 & 14.5 & 22.3 & 26.0 & 25.6 & 3.40 \\
Talking on CB & 16.2 & 14.0 & 29.8 & 23.7 & 16.2 & 3.10 \\
Drinking coffee & 18.2 & 17.4 & 28.0 & 19.5 & 16.9 & 3.00 \\
Singing or humming & 38.7 & 20.9 & 21.3 & 12.2 & 7.0 & 2.28 \\
Using tobacco products & 48.4 & 10.7 & 18.1 & 12.6 & 10.2 & 2.26 \\
Using over the counter drugs or & 83.3 & 3.8 & 5.3 & 4.8 & 2.9 & 1.40 \\
stimulants & 84.9 & 6.8 & 1.4 & 2.7 & 4.1 & 1.34 \\
Using prescription drugs & & & & & & \\
\hline
\end{tabular}

Note: Mean computed using $1=$ "not at all useful," $2=$ "slightly useful," $3=$ "moderately useful," $4=$ "fairly useful" and 5 = "Very Useful."

The second section of the questionnaire gathered information on drivers' perception of in-cabin air quality and their self-reported alertness levels during their current trips. Self-reported alertness is measured by the widely used Stanford Sleepiness Scale which has been shown to have high reliability and validity (Hoddes et al. 1973; Russo et al. 2003; Pizza 2004; Contardi et al. 2004; Bailes et al. 2006). Alertness was measured by "How did you feel when you were most tired while you were driving?" and the choices provided were the same as in the Stanford Sleepiness Scale. A standard eight-point coding system was also used and it ranged from $1=$ "Feeling active, vital, alert or wide awake" to 8 = "Asleep."

Driver's perception of air quality was measured primarily using the item: "Do you think that the air in the cabin is fresh?" and was measured using a three-point categorical scale with $1=$ "Yes," 2 = "No," and 3 = "Not sure." In addition, three secondary items were used to supplement the perception scores: "How do you quantify the irritation to your eyes, nose, throat, and skin, etc. during this trip?," "After how many hours did you feel that the air was not fresh?" and "How do you keep the air fresh?" The first item was measured using a five-point scale ranging from $1=$ "None" to $5=$ "Very Often." The second item was measured using four categories ranging from "less than four hours" to "10 hours or more." For the third item, respondents were asked to choose from different ventilation modes: "Natural (open windows)," "Recirculation," "Fresh air intake," or "Combination of the above."

In addition to the standard demographic data (e.g., age, gender), the final section gathered data on relevant health indicators from the respondents. First, the Epworth Sleepiness Scale was used to capture the general level of sleepiness and fatigue (Chervin 2003; Miletin and Hanly 2003; Kotterba et al. 2004; Bailes et al. 2006). Respondents were asked to rate the likelihood of falling asleep under seven nonphysical activities such as "sitting and reading" and their responses were coded from $0=$ "no chance" to 3 = "high chance." In addition, they were asked to indicate if they experienced any of the 20 common sleep-related medical symptoms or conditions, which could indicate they might be suffering from some kind of sleep disorder. These symptoms included snoring, choking, stopped breathing, forgetfulness, kicking legs, irresistible urge to sleep during the day, difficulty concentrating, forgetfulness, and morning headaches and are in Figure 5. 


\section{Statistical Analyses}

To determine if perceived air quality was associated with the health and alertness of drivers, the respondents were sub-divided into two groups: those who felt that the air was fresh and those who felt that the air was not fresh. Those who indicated that they were not sure of the air quality were excluded from further analyses. One Way Analysis of Variance was then performed using SPSS v11.5 (2002) to determine if significant differences existed between the two groups in terms of their Stanford Sleepiness Score, Epworth Sleepiness Score, number of sleep-related symptoms, and number of existing medical conditions.

Finally, an ordinal logit analysis was used to model the relationship between driver alertness during the trip and the two more pertinent perceived air quality indicators. The first is qualitative: "Do you think that the air in the cabin is fresh?" The second is physiological: "How do you quantify the irritation to your eyes, nose, throat, and skin, etc. during this trip?" Poor in-cabin air quality is likely to be associated with a driver experiencing these minor physiological symptoms. In addition to air quality indicators, some general driver information, such as age and gender, were included in the model. The model was estimated using SPSS v11.5 (2002) and because the program treats every independent variable as categorical, two simple dichotomous variables were created for the air quality indicators to simplify the analysis.

\section{DISCUSSION OF THE RESULTS}

As shown in Table 2, the most useful measure reported by drivers to help them stay alert while driving was taking a power nap, followed by stopping for fresh air and stretching, and stopping to eat and drink. A majority of the respondents also felt that cooling the truck cabin helped them stay alert. Other measures that were deemed to be useful (mean $\geq 3.0$ ) included listening to music and radio, and drinking coffee. Singing, and using tobacco products and drugs were not rated as useful by most truck drivers. ${ }^{1}$ Of these measures, stopping for fresh air and cooling the cabin are expected to be highly correlated with drivers' attempts to improve air quality and increase their alertness. Hence, it is encouraging to note that these were rated as useful by the majority of the drivers.

Drivers' perceptions of air quality in their trucks are reported in Figure 1. About half $(50.8 \%)$ felt that the air was fresh whereas about a quarter (24\%) said it was not. Moreover, $12.1 \%$ of the drivers reported they often or very often experienced irritations to their eyes, noses, throats, and skin as compared to $20.3 \%$ who reported experiencing irritations sometimes, $31.3 \%$ who reported rarely experiencing them, and $27.3 \%$ who reported no irritation. The most frequent mode of ventilation used was opening the window, which was reported by almost half $(49.6 \%)$ of the sample. The fresh air intake and recirculation mode of the vehicle ventilation system were used exclusively by only a small percentage ( $8 \%$ ) of the drivers while the rest $(42.4 \%)$ preferred using a combination of the different modes.

Drivers' self-rating of their state of alertness (sleepiness) during their trip was also elicited and reported in Figure 2. Only about $43.7 \%$ of the drivers reported that they were (1) "Feeling active, vital, alert, or wide awake" or (2) "Functioning at high level, but not at peak; able to concentrate" while $28.2 \%$ reported that they were (3) "Awake, but relaxed; responsive but not fully alert." More importantly, about $28.2 \%$ reported that they were clearly fatigued, with scores ranging from (4) "Somewhat foggy" to (8) "Asleep" while they were driving. These results suggest that a fairly large portion of truck drivers often continued to drive even when they felt tired and sleepy, a result that is consistent with several previous studies (Williamson et al. 1996; Arnold et al. 1997; Bass 2000; Häkkänen and Summala 2001; Hanowski et al. 2003; Dingus et al. 2001, 2006).

The results of administering the Epworth Sleepiness Scale (ESS) are reported in Figure 3. To simplify the analysis, the scores for the seven items in the ESS were added to obtain a composite score. Respondents were then classified by the following approach: a total score of nine or higher was considered to be poor and a score of six or less was considered to be good. ${ }^{2}$ Only $35.5 \%$ of 
In-Cabin Air Quality

Figure 1: Drivers' Perceptions of Air Quality

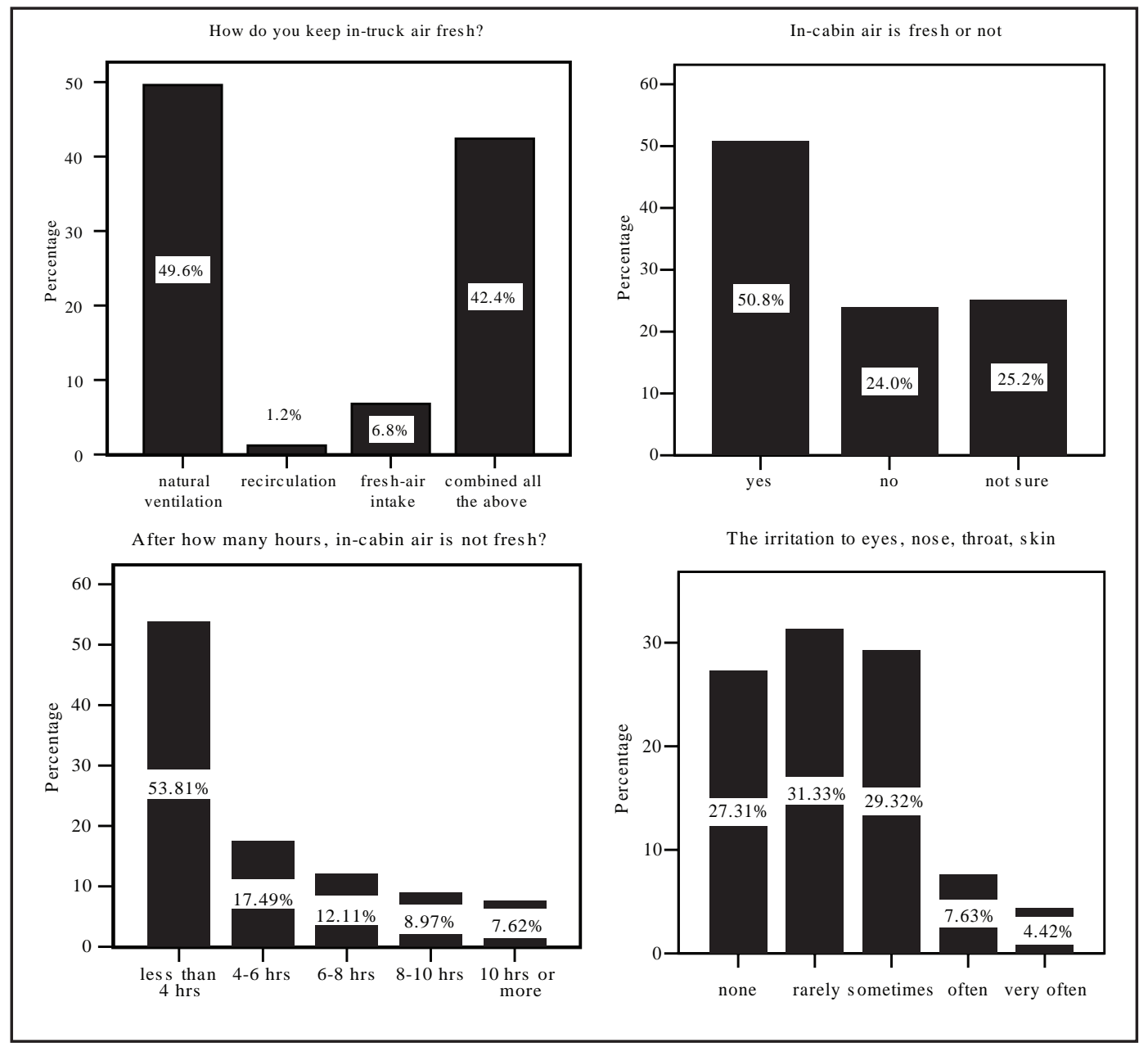

Figure 2: Stanford Sleepiness Scale

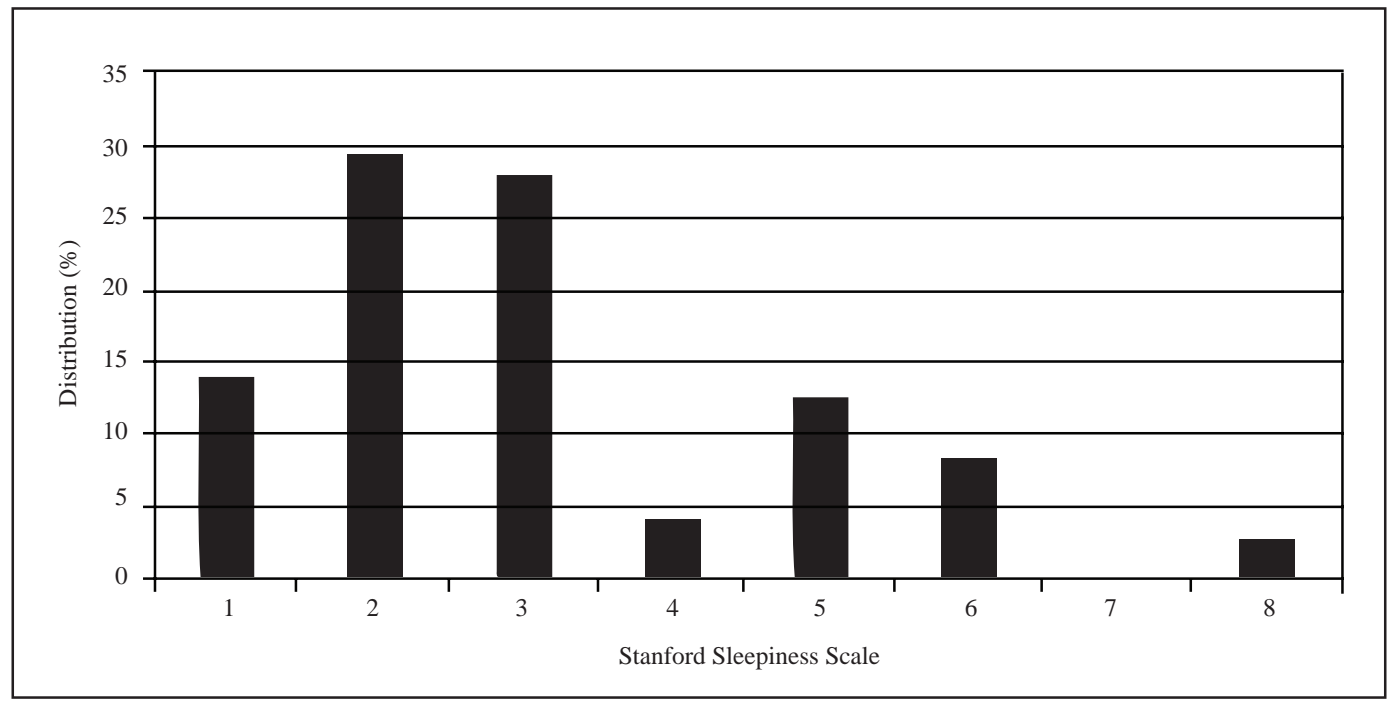


Figure 3: Epworth Sleepiness Scale

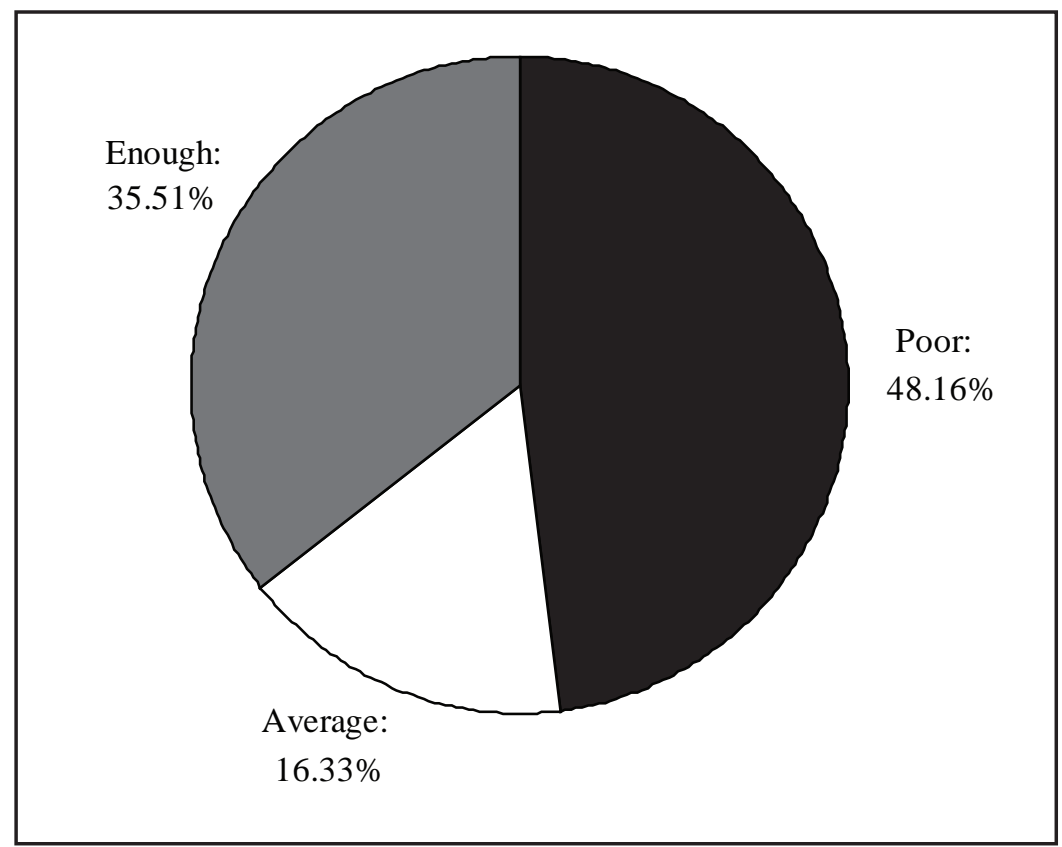

Figure 4: Self-Reported Sleep Disorders

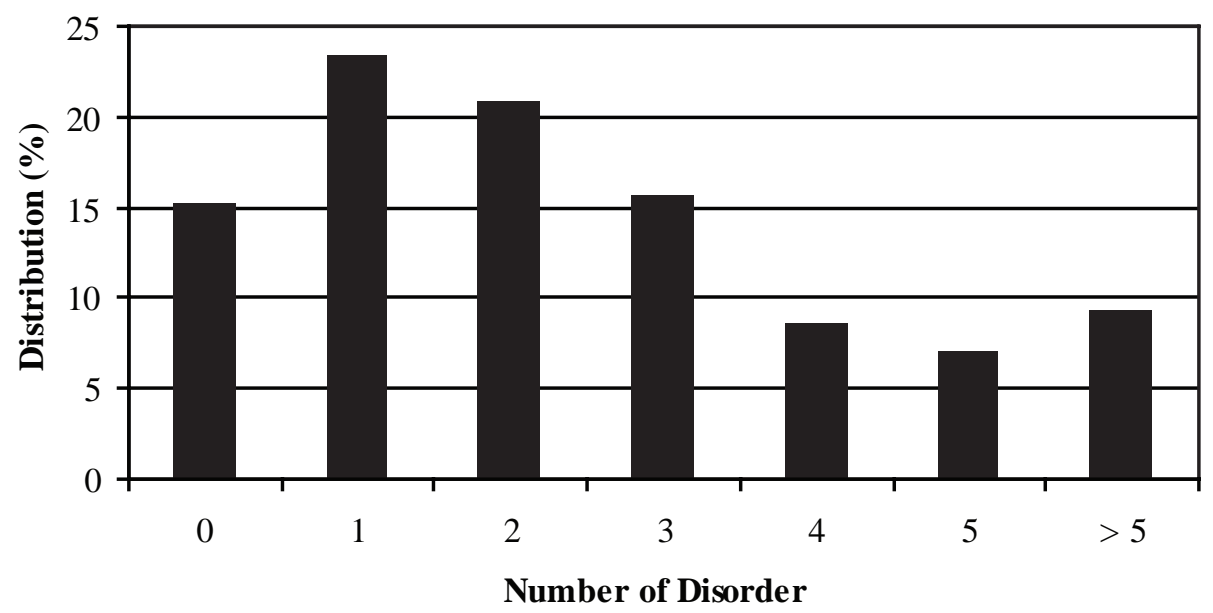


Figure 5: Self-Reported Medical Conditions

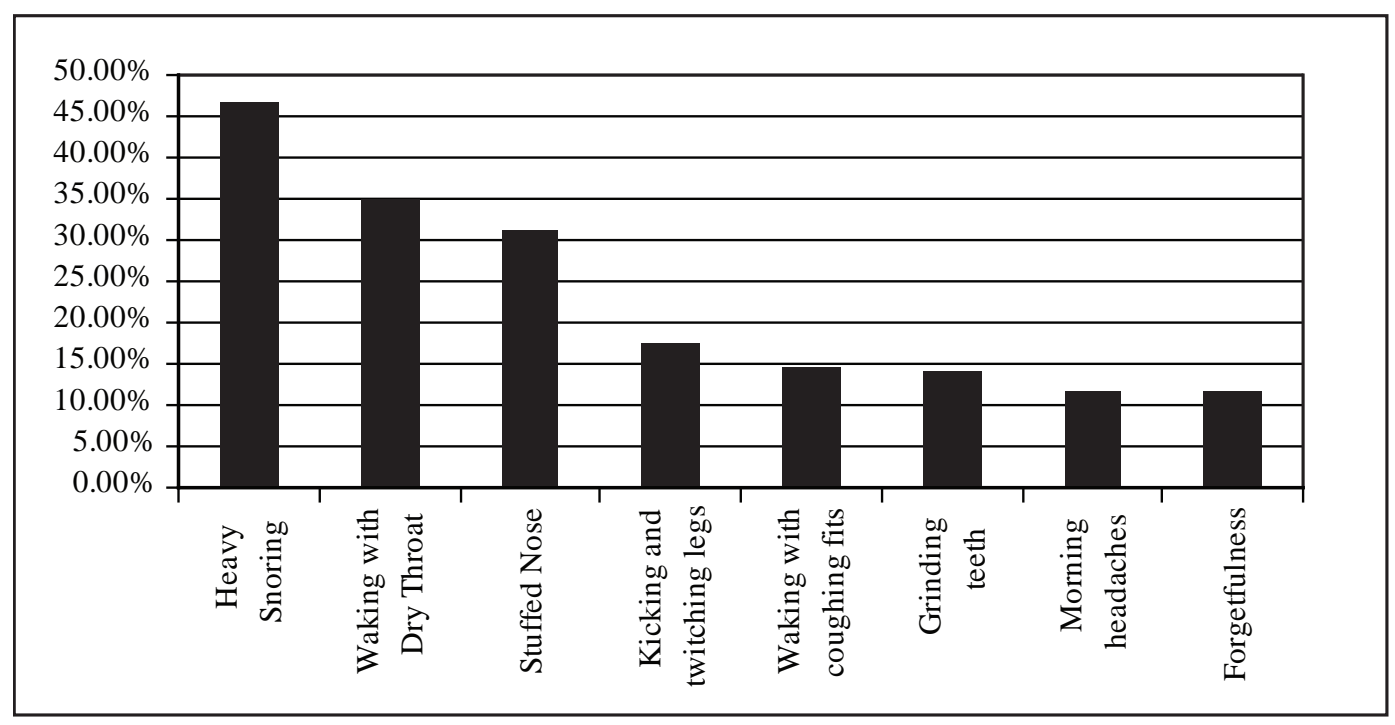

Table 3: Self-Reported Medical Conditions in Drivers

\begin{tabular}{l|c}
\hline Medical Conditions & Rates \\
\hline None & $32.1 \%$ \\
High blood pressure & $15.9 \%$ \\
Depression & $6.9 \%$ \\
Asthma \& Bronchitis & $6.1 \%$ \\
Heart problems & $4.5 \%$ \\
Chronic pain that interferes with sleep & $2.8 \%$ \\
Thyroid problems & $1.6 \%$ \\
Chronic fatigue syndrome & $1.2 \%$ \\
Liver problems & $0.8 \%$ \\
Alcohol or drug addiction & $0.8 \%$ \\
Kidney problems & $0.4 \%$ \\
\hline
\end{tabular}

the drivers reported a good score on ESS which implied that they probably did not suffer from any sleep-related problems. In contrast, nearly half (48.2\%) scored poorly on this scale, which indicated that they might have problems staying alert under normal circumstances and might suffer from poor quality of sleep.

To further examine their sleep-related problems, the numbers of disorders reported by the drivers are shown in Figure 4. A very large share $(85.1 \%)$ of the drivers reported experiencing at least one of the common symptoms showing they might be suffering from some form of sleep disorder. In addition, in Table 3, less than one-third (32.1\%) of the respondents reported that they did not have any existing medical conditions while a total of $41 \%$ reported having one of the conditions listed, which implies that at least $26.9 \%$ had some other medical conditions that were not included in the list. Of the medical conditions, $15.9 \%$ had high blood pressure, $6.9 \%$ experienced depression, $6.1 \%$ had asthma or bronchitis, and $4.5 \%$ suffered from heart problems.

To determine if perceived air quality in the truck cabin was associated with the drivers' health and alertness, the Analysis of Variance procedure was performed between those who rated the air as 
fresh and those who rated the air as not fresh. First, truck drivers who rated the air as fresh reported less irritation to their eyes, noses, throats, skin, etc. (Mean, $M=1.9$ ) than those who rated the air as not fresh $(M=2.9)$ and the difference was statistically significant $(\mathrm{p}<0.01)$. Second, drivers who rated the air in their cabins as fresh reported a better score on the Stanford Sleepiness Scale $(M=2.69)$ than those who rated the air as not fresh $(M=3.74)$ and the difference in the two means was statistically significant $(\mathrm{p}=0.022)$. Third, those who rated the air as fresh scored better on the Epworth Sleepiness Scale $(M=8.1)$ than those who rated the air as not fresh $(M=9.6)$, and this difference was also statistically significant $(\mathrm{p}=0.038)$. Finally, drivers who rated the air as fresh also reported fewer sleep-related symptoms $(\mathrm{M}=2.2)$ than those who rated the air as not fresh $(\mathrm{M}$ $=3.2)$ and this difference was statistically significant $(\mathrm{p}=0.010)$. The perception of in-cabin air quality, however, was not related to the number of medical conditions that the drivers had. The last result is not surprising because, unlike the other four health indicators, most of the medical conditions surveyed are not directly related to in-cabin air quality but are included in the survey for completeness.

Finally, an ordinal logit model was estimated to examine the effects of perceived air quality on driver alertness during the trip. This particular performance indicator is chosen because it has the greatest direct impact on road safety among all the health and alertness measures examined. The estimation results are reported in Table 4. With one exception, all other thresholds $(\mu)$ delineating the different levels of alertness were found to be statistically significant whereas demographic variables, such as age and gender, were found to be insignificant. The latter results are not surprising, since age and gender are likely to have greater impacts on long-term health outcomes than on alertness during a single trip. Our results show that drivers' alertness during a trip is negatively and significantly correlated with their qualitative perception of in-cabin air quality not being fresh and their selfreported physiological symptoms (irritation to eyes, nose, throat, skin, etc).

Table 4: Estimation Results

\begin{tabular}{|c|c|c|}
\hline $\begin{array}{l}\text { Number of Observations } \\
\text { Chi-Square } \\
\text { P-value }\end{array}$ & $\begin{array}{l}235 \\
18.23 \\
<0.0001\end{array}$ & \\
\hline Variables & Coefficients & Standard Errors \\
\hline$\mu_{1}$ & 1.020 & 0.95 \\
\hline$\mu_{2}$ & $2.85^{*}$ & 0.97 \\
\hline$\mu_{3}$ & $3.75^{*}$ & 0.99 \\
\hline$\mu_{4}$ & $3.87 *$ & 1.00 \\
\hline$\mu_{5}$ & $4.02 *$ & 1.01 \\
\hline$\mu_{6}$ & $4.80^{*}$ & 1.07 \\
\hline Driver Age & -0.080 & 0.13 \\
\hline Driver Gender & -0.160 & 0.77 \\
\hline \multicolumn{3}{|c|}{ Air in Cabin is Fresh (Reference: Not Sure/No) } \\
\hline Yes & $-0.60 *$ & 0.31 \\
\hline \multicolumn{3}{|c|}{ Irritation to Eyes, Nose, Throat, Skin, etc (Reference: Sometimes/Often/Very Often) } \\
\hline None/Rarely * & $-0.59 *$ & 0.20 \\
\hline
\end{tabular}

Note: $*$ denotes statistically significant at $\alpha=0.05$ level 


\section{CONCLUDING REMARKS}

Despite its importance to the Canadian and American economies, little research has been conducted to examine the quality of the air in truck cabins which are workplaces for over three million people. Additionally, there is currently no regulation requiring minimum air quality at this important workplace. Previous studies have found that air quality in commercial truck cabins may not be clean and comparable to standards for other workplaces and indoor environments (Tan et al. 2006a, b).

In this study, a questionnaire survey was administered to 253 truck drivers to gather information on their perception of air quality in their cabins. The results were related to their self-reported health and alertness. Only about half of the drivers surveyed rated the air in their cabins as fresh. More importantly, those who rated the air as fresh reported less irritation to their eyes, noses, throats, and skin, scored better in both the Stanford Sleepiness Scale and the Epworth Sleepiness Scale, and reported fewer sleep-related medical symptoms. Multivariate analysis using an ordinal logistic model found that drivers' alertness during a trip is significantly correlated with their qualitative assessment of the air quality in their cabins and their self-reported symptoms of breathing poor quality air (irritations to nose, throat, eyes, and skin).

This study establishes only a correlation between perceived air quality and self-reported health and alertness with two limitations. First, it does not establish a causal relationship between perceived air quality and self-reported health and alertness. Therefore, more comprehensive studies are needed to establish the underlying causal relationship and the strength of this relationship. Second, it relies on drivers self-report of health and alertness and not on actual medical records which are extremely difficult to obtain. It also examines drivers' perception of air quality. Although physical measurement of air quality is possible, it is beyond the scope of this study. Given these limitations, care should be exercised in generalizing the results. Nevertheless, the results raise questions about the quality of the air in truck cabins and the need for further research. 


\section{APPENDIX}

\section{Survey on Air Quality in Trucks}

There is no right or wrong answer and the survey is completely confidential, so please tick the box that best represents your view.

\section{Section One: (General Driving)}

1. How long have you been driving a truck?
$\square 0-2$ yrs $\square 3-5$ yrs
$\square$ 6-10 yrs
$\square 10$ yrs or more

2. Are you primarily a short haul or long haul driver?
$\square$ Mostly short haul
$\square$ Very mixed
Mostly long haul

3. How many days do you usually drive for work in a week?
$\square 3$ days or less
$\square 4$ days
5 days
6 days
7 days

4. How many hours do you usually drive for work in a day?
$\square$ 0-3 hrs
4-8 hrs
$\square$ 9-11 hrs
$12-15 \mathrm{hrs}$
$\square 16-19 \mathrm{hrs}$
20 hrs or more

5. Do you usually drive alone?

$\square$ Yes $\quad \square$ No, I usually have a passenger $\square$ No, I usually have a co-driver

6. How many hours of sleep do you usually get in a 24 hour period?
$\square 4 \mathrm{hrs}$ or less
$\square$ 4-6 hrs
$7-9 \mathrm{hrs}$
$10 \mathrm{hrs}$ or more

7. How often do you sleep in the sleeper berth in the truck?

$\square$ Less than once a week $\square$ 1-2 times a week $\square$ 3-4 times a week $\square$ 5-6 times a week $\square$ everyday

8. How useful do you think the following measures are in helping you stay alert while driving? $(1=$ not useful at all, $2=$ slightly useful, $3=$ moderately useful, $4=$ fairly useful, $5=$ very useful)
a. Cooling the truck cabin
b. Drinking coffee
c. Listening to $\mathrm{AM} / \mathrm{FM}$ radio
d. Listening to music on cassette or CD

$\begin{array}{lllll}1 & 2 & 3 & 4 & 5 \\ 1 & 2 & 3 & 4 & 5 \\ 1 & 2 & 3 & 4 & 5 \\ 1 & 2 & 3 & 4 & 5 \\ 1 & 2 & 3 & 4 & 5 \\ 1 & 2 & 3 & 4 & 5 \\ 1 & 2 & 3 & 4 & 5 \\ 1 & 2 & 3 & 4 & 5 \\ 1 & 2 & 3 & 4 & 5 \\ 1 & 2 & 3 & 4 & 5 \\ 1 & 2 & 3 & 4 & 5\end{array}$




\section{Section Two: Information on Current Trip}

Route: From To

Time: Start End

1. How many stops or breaks (including sleeping) from driving did you take during the trip?

$\square$ Never $\square$ 1-2 $\square$ 3-4 $\square$ 5-6 $\square 7$ or more

2. How long did you sleep during the trip?

$\square$ less than $4 \mathrm{hrs} \quad \square$ 4-6 hrs $\square$ 6-8 hrs $\square 8$-10 hrs $\square 10 \mathrm{hrs}$ or more

3. When did you sleep? $\square$ daytime only $\square$ evening only $\square$ a bit of both

4. How did you feel when you were the most tired while you were driving?

$\square$ Feeling active, vital, alert, or wide awake

$\square$ Functioning at high levels, but not at peak; able to concentrate

$\square$ Awake, but relaxed; responsive but not fully alert

$\square$ Somewhat foggy, let down

Foggy; losing interest in remaining awake; slowed down

Sleepy, woozy, fighting sleep; prefer to lie down

$\square$ No longer fighting sleep, sleep onset soon; having dream-like thoughts

$\square$ Asleep

5. How do you keep in-truck air fresh?

$\square$ Natural ventilation (open windows)

$\square$ Recirculation mode

Fresh-air intake mode

Combined all the above

6. Do you think that the air in the cabin is fresh?

$\square$ Yes $\quad \square$ No $\quad \square$ Not sure

If No, please specific why:

7. After how many hours, do you feel in-truck air is not fresh enough and you have to open windows?
less than $4 \mathrm{hrs}$
4-6 hrs
6-8 hrs
8-10 hrs
$10 \mathrm{hrs}$ or more

8. How do you quantify the irritation to your eyes, nose, throat, skin etc. during this trip?
$\square$ None
Rarely
$\checkmark$ Sometimes
$\square$ Often
very often

\section{Section Three: General Health}

1. Age: $\square$ under $25 \quad \square 25-34 \quad \square 35-44 \quad \square$ 45-54 $\square 55-64 \quad \square 65$ \& over

2. Sex: $\square$ Male $\quad \square$ Female

3. Do you smoke? $\quad \square$ No $\square$ Light $\square$ Moderate $\square$ Heavy

4. Do you drink (alcohol)? $\square$ No $\square$ Light $\square$ Moderate $\square$ Heavy 
5. How likely are you to doze off or fall asleep in the following situations, in contrast to feeling just tired? This refers to your usual way of life in recent times. Even if you have not done some of these things recently try to work out how they would have affected you.

$$
(0=\text { no chance; } 1=\text { slight } \text { chance } ; 2=\text { moderate chance; } 3=\text { high chance })
$$
a. Sitting and reading
$\begin{array}{llll}0 & 1 & 2 & 3\end{array}$
b. Watching TV
$\begin{array}{llll}0 & 1 & 2 & 3\end{array}$
c. Sitting inactive in a public place (e.g. a theatre or a meeting)
$\begin{array}{llll}0 & 1 & 2 & 3\end{array}$
d. As a passenger in a vehicle for an hour without a break
$\begin{array}{llll}0 & 1 & 2 & 3\end{array}$
e. Lying down to rest in the afternoon when circumstances permit
$\begin{array}{llll}0 & 1 & 2 & 3\end{array}$
f. Sitting and talking to someone

$\begin{array}{llll}0 & 1 & 2 & 3\end{array}$
g. Sitting quietly after a lunch without alcohol
$\begin{array}{llll}0 & 1 & 2 & 3\end{array}$
h. In a vehicle, while stopped for a few minutes in traffic

$\begin{array}{llll}0 & 1 & 2 & 3\end{array}$

6. Please check any of the following that you have experienced (or anyone else like your spouse or driving partners has reported about you) on regular basis related your sleep.
Snoring that disturbs others
Choking
Stopped breathing
Waking with coughing fits
Tightness in chest
$\square$ Throat dry when wake up
Forgetfulness
Sputtering or gagging
Sleep-walking
Difficulty breathing
Sleep-talking
Difficulty concentrating
Severe recurrent nightmares
Grinding teeth
Irresistible urge to sleep during the day
Kicking and twitching legs
Gasping
Acting out your dreams
Morning headaches
Congested nose or allergy

7. Please indicate any of the following medical conditions that you have.
$\square$ High blood pressure
$\checkmark$ Alcohol or drug addiction
Liver problems
Kidney problems
Thyroid problems
Chronic fatigue syndrome
Heart problems
Chronic pain that interferes with sleep
Depression
Seizures
Asthma or Bronchitis
$\square$ None

8. If you have any comments or suggestions, please add in below. 
In-Cabin Air Quality

\section{Endnotes}

1. It should be noted that this question only asked for the drivers' perception of the usefulness of using over the counter drug, which is legal, and not on its use. Therefore, social desirability bias is not expected to be significant.

2. http://www.stanford.edu/ dement/key html

\section{References}

Akerstedt, T. "Fatigue and Accidents in Transport Operations." Journal of Sleep Research 9(4), (2000): 395.

Alberts, W. "Indoor Air Pollution: NO, NO2, CO, CO2." Journal of Allergy and Clinical Immunology 94, (1994): 289-295.

American Trucking Associations. "The U.S. Truck Driver Shortage: Analysis and Forecasts." 2005. Available online at http://www.truckline.com/NR/rdonlyres/E2E789CF-F308-463F-88310F7E283A0218/0/ATADriverShortageStudy05.pdf.

Arnold, P., L. Hartley, A. Corry, D. Hochstadt, F. Penna and A. Feyer. "Hours of Work, and Perceptions of Fatigue Among Truck Drivers.” Accident Analysis \& Prevention 29 (4), (1997): 471-477.

Baas, P., S. Charlton and Bastin. "Survey of New Zealand Truck Driver Fatigue and Fitness for Duty." Transportation Research F 3 (4), (2000): 185-193.

Bailes, S., E. Libman, M. Baltzan, R. Amsel, R. Schondorf and C. Ficten. "Brief and Distinct Empirical Sleepiness Scale.” Journal of Psychosomatic Research 60, (2006): 605-613.

Cheng, X., Z. Tan, R. Tay and W Yuan. "Air Quality in Transportation Cabins - Part I: How Much Do We Know about It?” ASHRAE Transactions 112(2), (2006): 505-517.

Chervin, R. "Editorial: Epworth Sleepiness Scale?” Sleep Medicine 4, (2003): 175-176.

Contardi, S., D. Pizza, E. Sancisi, S. Mondini and F. Cirignotta. "Reliability of a Driving Simulation Task for Evaluation of Sleepiness." Brain Research Bulletin 63, (2004): 427-431.

Dingus, T., V. Neale, S. Klauer, A. Petersen and R. Carroll. "The Development of a Naturalistic Data Collection System to Perform Critical Incident Analysis: An Investigation of Safety and Fatigue Issues in Long-Haul Trucking." Accident Analysis \& Prevention 38(6), (2006): 1127-1136.

Dingus, T. et al. Impact of Sleeper Berth Usage on Driver Fatigue. Virginia Tech Transportation Institute, Blacksburg, 2001.

Dreher, K. "Health and Environmental Impact of Nanotechnology: Toxicological Assessment of Manufactured Nanoparticles.” Toxicological Sciences 77, (2004): 3-5.

Feyer, A., A. Williamson and R. Friswell. "Balancing Work and Rest to Combat Driver Fatigue: An Investigation of Two-up Driving in Australia." Accident Analysis \& Prevention 29(4), (1997): 541-553.

Galatsis, K., W. Wlodarski, Y. Li, and K. Kalantar-zade. "Vehicle Cabin Air Quality Monitor Using Gas Sensors for Improved Safety." IEEE Proceedings of the 2000 Conference on Optoelectronic and Microelectronic Materials and Devices, 65-68. 
Gander, P., N. Marshall, I. James and L. Quesne. "Investigating Driver Fatigue in Truck Crashes: Trial of A Systematic Methodology." Transportation Research Part F 9 (1), (1998): 65-76.

Gander, P., R. Barnes, K. Gregory, R. Graeber, L. Cornell and M. Rosekind. "Flight Crew Fatigue III: North Sea Helicopter Air Transport Operations." Aviation, Space and Environmental Medicine 69 (9), (1998): B16-25.

Gillberg, M., G. Kecklund and T. Åkerstedt. "Sleepiness And Performance of Professional Drivers in A Truck Simulator: Comparisons Between Day and Night Driving." Journal of Sleep Research 5, (1996): 12-15.

Häkkänen, H. and H Summala. "Fatal Traffic Accidents Among Trailer Truck Driver and Accident Causes as Viewed By Other Truck Driver." Accident Analysis \& Prevention 33 (2), (2001): 187 196.

Hanowski, R., W. Wierwille and T. Dingus. “An On-Road Study to Investigate Fatigue in Local/ Short Haul Trucking." Accident Analysis and Prevention 35, (2003): 153-160.

Hoddes, E., H. Zarcone and R. Smythe. "Quantification of Sleepiness: A New Approach." Psychophysiology 10 (4), (1973): 431-436.

Kotterba, S., N. Mueller, M. Leidag, W. Widdig, K. Rasche, J. Malin, G. Schultze-Werninghaus and M. Orth. "Comparison of Driving Simulator Performance and Neuro-Psychological Testing in Narcolepsy.” Clinical Neurology and Neurosurgery 106, (2004): 275-279.

MDH, Carbon Dioxide, 2004. Minnesota Department of Health Fact Sheet. IC\# 141-1422: 1-2.

Miletin, M. and P. Hanly. "Measurement Properties of the Epworth Sleepiness Scale." Sleep Medicine 4, (2003): 195-199.

NIOSH. "Work-Related Roadway Crashes - United States, 1992-2002." Mobility and Mortality Weekly Report 53 (12), (2004): 260-264.

Norbäck, D., I. Michel and J. Widström. "Indoor Air Quality and Personal Factors Related to the Sick Building Syndrome.” Scandinavian Journal of Work, Environment and Health 16 (2), (1990): 121-8.

OSHA. 1995. Standards-29 CFR. Table Z-1 Limits of Air Contaminants-1910.1000 Table Z-1.

Penney, D. Carbon Monoxide Poisoning. Taylor \& Francis, Boca Raton, 2007.

Pizza, F., S. Contardi, B. Mostacci, S. Mondini and F. Cirignotta. "A Driving Simulation Task: Correlations with Multiple Sleep Latency Test.” Brain Research Bulletin 63, (2003): 423-426.

Russo, M., M. Thomas, D. Thorne, H. Sing, D, Redmond, L. Rowland, D. Johnson, S. Hall, J. Krichmar and T. Balkin. "Oculomotor Impairment During Chronic Partial Sleep Deprivation." Clinical Neurophysiology 114, (2003): 723-736.

Samet, L. and W. Cushing. "A Study of Respiratory Illnesses in Infants and NO2 Exposure." Archives of Environmental Health 47 (1), (1997): 57-63.

Sato, S. “Air Quality in Auto-Cabin.” R\&D Review of Toyota CRDL 39(1), (2002): 36-43.

Schwarzberg, M.N. "Carbon Dioxide Level as Migraine Threshold Factor: Hypothesis and Possible Solutions.” Medical Hypotheses 41(1), (1993): 35-36. 
In-Cabin Air Quality

Simoni M., L. Carrozzi, S. Baldacci, et al. "The Po River Delta (North Italy) Epidemiological Study: Effect of Pollutant Exposure on Acute Respiratory Symptoms and Respiratory Function in Adults." Archives of Environmental Health 57, (2002): 130-136.

SPSS V11.5. Statistical Package for Social Sciences (SPSS for Windows), Release 11.5. SPSS Inc., Chicago, 2002.

Tan, Z., X. Cheng and R. Tay. "Air Quality in Transportation Cabins - Part II: Air Quality in a Truck-Cabin.” ASHRAE Transactions 112 (2), (2006): 518-525.

Tan, Z., X. Cheng, X. Wang and R. Tay. “Air Quality in Commercial Truck Cabin.” Transportation Research Part D 11, (2006): 389-395.

Tan, Z. and R. Tay. "Characterization of PM2.5 in a Commercial Truck Cabin." Transportation Research Part D 13, (2008): 54-58.

Thibeault, C. "Special Committee Report: Cabin Air Quality." Aviation, Space and Environmental Medicine 68, (1997): 80-82.

Townsend, C. and R. Maynard. "Effects on Health of Prolonged Exposure to Low Concentrations of Carbon Monoxide.” Occupational and Environmental Medicine 59, (2002): 708-711.

Transport Canada. Road Safety Vision 2010. Transport Canada, Ottawa, 2002.

Transport Canada. Transport Canada Annual Report - Transportation in Canada 2004. Transport Canada, Ottawa, 2004.

Wallace, L. and K. Smith. "Exposure to Particles." Ott et al. eds. Exposure Analysis. Boca Raton: Taylor and Francis (2007).

Wargocki, P., D. Wyon, Y. Baik, G. Clausen and P. Fanger. "Perceived Air Quality, Sick Building Syndrome (SBS) Symptoms and Productivity in an Office with Two Different Pollution Loads." Indoor Air 9 (3), (1999): 165-179.

Williamson, A., A. Feyer, R. Mattick, R. Friswell and S. Finlay-Brown. "Developing Measures of Fatigue Using an Alcohol Comparison to Validate the Effects of Fatigue on Performance." Accident Analysis \& Prevention 33 (3), (2001): 313-326.

Williamson, A., A. Feyer and R. Friswell. "The Impact of Work Practices on Fatigue in Long Distance Truck Drivers." Accident Analysis \& Prevention 28 (6), (1996): 709-719

\section{Acknowledgements}

Financial support for the project was provided by the Natural Science and Engineering Research Council of Canada, the Alberta Motor Association and the Centre for Transportation Engineering and Planning. However, the views expressed by the authors do not necessarily reflect those of the sponsors. The authors also thank the management and staff of Economy Carrier Limited and the Road King and Husky truck stops for their kind assistance. 
Dr. Richard Tay, P.Eng., is the AMA chair and professor in road safety in the Department of Civil Engineering at the University of Calgary. He graduated with a B.S. from Texas Tech University, a M.S. from Stanford University and a Ph.D. from Purdue University. His research focuses on the analysis and prevention of road crashes. He serves on the editorial board of several journals including Accident Analysis and Prevention, Journal of the Australian College of Road Safety and Journal of Advanced Transportation.

Dr. Zhongchao Tan, P.Eng., is an assistant professor of environmental engineering at the Department of Mechanical Engineering at the University of Calgary. He received his B.S. and M.S. from Tsinghua University and his Ph.D. from the University of Illinois at Urbana-Champaign. His research focuses on aerosol/particulate air pollution characterization and control and waste management. He won first place in the Ph.D. student research award from ASAE in 2004 and ASABE superior paper award in 2006. He is the associate editor of two journals.

Ms. Xiaoying Cheng, P.Eng., is an air quality specialist with Jacque Whitford Ltd. She received her B.S. from Taiyuan Institute of Technology and her M.S. from the University of Calgary. She has extensive experience in air dispersion modeling and indoor air quality. 